\title{
Reassuring Feasibility of Using Bourdieusian Sociocultural Paradigm for Literary Translation Study
}

\author{
M.Yuseano Kardiansyah ${ }^{1,2, *}$ Aprinus Salam ${ }^{1}$ \\ ${ }^{1}$ Faculty of Cultural Sciences, Universitas Gadjah Mada, Yogyakarta, Indonesia \\ ${ }^{2}$ Faculty of Arts and Education, Universitas Teknokrat Indonesia, Bandarlampung, Indonesia \\ *Corresponding author.Email: yuseano@teknokrat.ac.id
}

\begin{abstract}
This study aims to reassure the feasibility of applying Pierre Bourdieu's sociocultural paradigm for conducting literary translation study. Influenced by the fact that literary translation scholars in Indonesia have not found the significance of the sociocultural approaches, this study intends to philosophically assess the 'basic assumptions' of the Bourdieusian genetic structuralism paradigm to understand further its fundamental thoughts about literature and human culture. In accordance, those basic assumptions can reveal whether or not that paradigm is compatible to be applied in translation study. As library research, extensive reading is a primary technique to collect the data needed. The data in the form of theoretical explanation and scientific analysis results are analyzed cohesively to reach an accurate understanding of genetic structuralism's basic assumptions and how literary translation scholars possibly apply it. Eventually, this study proves that the Bourdieusian sociocultural paradigm has basic assumptions that can lead a translation study to explore the production process of literary translation, translation agents' role, and the origin of agents' particular action in translation practice. Studies that have been developed by translation scholars around the world.
\end{abstract}

Keywords: Bourdieusian sociocultural paradigm, genetic structuralism, literary translation, translation study, basic assumptions

\section{INTRODUCTION}

Among many paradigms in the sociocultural study of translation, Bourdieusian genetic structuralism has become an influential philosophical base that influences literary translation study development. Literary translation scholars have been adapting this based on their scientific exploration (Wolf [1]; Gouanvic [2] and [3]; Inghilleri [4]; Hanna [5] and [6]; Sapiro [7] and Xu [8]), in which their thoughts and studies have given significant impacts to the development of translation study through a sociocultural perspective. In the context of literary study, Bourdieusian genetic structuralism, as a paradigm, has also been purposively occupied by the literary researchers to conduct an interdisciplinary study (i.e., sociology of literature). Therefore, it enables their studies to result various findings as the outcome. In that case, the domain of literary translation study is where such a condition common to be found.

Munday [9] confirms that the Bourdieusian approach can help to theorize the translator's role in producing translated texts. For him, Bourdieu's concepts such as field, habitus, capital, and illusio can elaborate on the significance of translator and the genesis of their practice in the field of cultural production. However, the potential of the Bourdieusian sociocultural paradigm for literary translation study has not attracted the attention of literary scholars in Indonesia. The sociocultural study has not that much conducted toward translated work. It is proven by Dewi [10], in which she describes how translation study oriented to the process, and agents have not been enormously developed by the translation scholars in Indonesia. Thus, there lies a huge probability that the translation study domain still leaves a lot of empty spaces to be explored further.

The problem that occurs is probably caused by the hesitation of whether a particular approach, such as the Bourdieusian sociocultural paradigm, is potentially applicable in translation study. There must be a rooted philosophical investigation to delineate its basic assumptions toward the cultural product's existence and the agent who produces it. This study can enable us to see the relevance and significance of the Bourdieusian paradigm to a specific research problem, such as translation. Therefore, this can help understand the paradigm and eventually know in what context the paradigm can be used to support a translation study. However, before discussing it deeply, the concept of 'paradigm' must be explained more comprehensively.

\section{Paradigm in Theory}

From a general perspective, Ahimsa-Putra [11] defines paradigm as a set or unity that is formed based on the logical interrelation of concepts in the level of thought. Here, that set of concepts refers to a term called the framework of thought. In that sense, such a framework of thought can be used by someone who can reflect his thought to understand, interpret, and explain a problem or reality in life. In line with that perception, Kuhn [12] 
believes that paradigm refers to the past scientific achievements used as a foundation for further practice in conducting firm research or normal science. In this context, a paradigm can provide models, which have been developed in a particular tradition of scientific research, to be adopted or adapted by current researchers. Therefore, it confirms that paradigm is a framework of thought that can be used (either adopted or adapted) by the researchers as a foundation to understand, interpret and explain problems and realities in life, specifically in a particular scientific field.

However, as a set of concepts, it is undeniable that attention must also be paid to each of those concepts, for they have become the elements that form a framework of thought. Related to that, in his explanation, Kuhn has implied them by mentioning some terms, such as law, theory, application, and instrumentation. Even so, besides they are not further elaborated, Kuhn's point of view is departed from the science field instead of the sociocultural field, thus even if Kuhn has given a detail explanation, it is presumably incompatible with being taken alongside the discussion of paradigm in the sociocultural study such as literary study. Henceforth, the notion of Ahimsa-Putra (even though Kuhn also influences it) about paradigm elements is believed more suitable in this context, for it departs from the sociocultural tradition of the scientific field.

According to him, there are nine inter-related main elements of a paradigm in the sociocultural study as follow: basic assumption, value, model, research problem, concepts, method of research, method of analysis, the result of analysis (theory), and representation. However, this present study focuses on the concept of basic assumption as the foundation of a framework of thought, for it is a 'taken for granted' ontological belief for understanding or answering problems in a specific scientific field.

Therefore a study of paradigms is an attempt to elucidate those elements, or at least one of them, to provide a more precise and more rooted understanding of the existence of paradigms in a particular scientific field. According to Kuhn, studying paradigms enables later scholars to base their study upon the same rules and standards for scientific practice. However, it is undeniable that a firm actual scientific practice can realize another paradigm or subparadigm as an outcome. So that it eventually holds both genesis and continuation of a particular research tradition. To be more specific, Faruk [13] purposively sees paradigm to have the same meaning as literary criticism. He believes that various literary criticisms can belong to one primary paradigm due to their similar basic assumptions within every theoretical and methodological implication. The term literary criticism, in this case, generally refers to the formal study and discussion of literary works and its related factors. This kind of study will eventually involve judgment and explanation of the importance and meaning of literary works. As a formal study, it is based on a particular paradigm to be its framework of thought, and then it can result in a specific theory as the outcome of the analysis. On that point, Kuhn believes that a theory can be accepted as a paradigm if it is better than or as reliable as other paradigms due to its ability to solve specific problems in a particular field of the scientific tradition. So that Faruk's point of view is reasonable to the extent that the so-called literary criticism is the product and producer of the paradigm itself. This view is in line with Munday's claim previously, in which the Bourdieusian framework potentially solves problems left by the others in literary translation study.

Eventually, the above explanation can be a parameter for analyzing a paradigm's tendency in conceptualizing literary work and problems in the literary field itself. In this paper, Bourdieu's genetic structuralism paradigm will be analyzed based on that framework, in which the result can show whether or not its basic concepts form it as a reliable framework of thought for literary translation study. Besides, this paper is also focused on the basic assumptions that can lead to understanding this paradigm's compatibility with literary translation study.

\section{METHOD OF RESEARCH}

\subsection{The Material and Formal Objects}

Based on the definition [14], the material object is a particular object to be investigated or observed in scientific study, while the formal object is an angle to be studied from the material object. Hence, in this present study, the material object is the Bourdieusian genetic structuralism paradigm, and the formal object is the basic assumption of this paradigm.

\subsection{Data Collection and Analyzing Technique}

As it is library research, this study attempts to find out many relevant data related to the Bourdieusian sociocultural paradigm's basic assumptions on literary translation agents and the field of research in cultural production. The data are collected by closely reading Pierre Bourdieu's writings and other scientific writing related to Bourdieu's thoughts. Those data are selected and categorized to be analyzed for reaching the aim of the research.

The paradigm's basic assumptions are analyzed by analyzing data from books and journal articles that explicate a set of concepts of Bourdieu's genetic structuralism paradigm. It is conducted to understand the framework of thought developed by Bourdieu on cultural production, including literary translation. More than that, the analysis is also developed to assess the feasibility of that paradigm for literary translation study.

\section{RESULTS AND DISCUSSION}

Pierre Bourdieu is an expert in the sociology of cultural production, which tries to develop two epistemological models: 'subjectivism' and 'objectivism'. He then results in genetic sociology or genetic structuralism theory by proposing a base of thought so-called 'the objectivity of the subjective'. Furthermore, Bourdieu [15] explicitly states that his framework of thought is a combination between an analysis of the objective social structure and an analysis of the socially constituted mental structure's genesis, 
internalized into particular individuals, which triggers practice.

Generally, this theory tries to answer every problem, including social conditions of production, circulation, and consumption of symbolical goods, in which literary work is attached inside. Therefore the context of studies related to this paradigm includes:

1. The exploration upon work producers in terms of their strategies and trajectories, based on their individual and class habitus, as well as their objective position within a field;

2. The analysis of the field's structure (position of the writers or artists), consecration and legitimation which make cultural products as they are (public, publisher, critics, gallery, and academy.);

3. The analysis of a specific field's position (such as the cultural field) concerning a broader field of power such as economy, and politics.

In accordance, Karnanta [16] views that Bourdieu's field of cultural production theory is developed from his thought about 'practice' formulated to analyze and understand the process of generating social structure based on elements in social space. He further elaborates that Bourdieu sees social space as space where the social interaction process happens in agents with various characteristics but systematically connected. Contextually, this paradigm is seen to have some essential basic assumptions about its 'object of research (literary field)' and about 'human (literary agent)'.

\section{Basic Assumptions on Object of Research}

The research object in this context does not mainly refer to literary work but the literary field instead. The science of the literary field, according to Bourdieu, is a kind of site analysis that determines every position based on a distinctive properties system that shows one position can be situated among others. Furthermore, Bourdieu sees the literary field as a 'field of force', along with a 'field of struggle' that tends to transform or conserve this field of force. This field is formed by objective relations based upon different positions the agents possess during the struggle to defend or improve their position. The strategy used for that struggle eventually depends on the force and position of agents in the power relations.

The field's structure refers to a space of positions, which is the structure of capital distribution of specific properties that supports the agents' success in field and wins the external profit (financial) or specific profit (prestige). The structure of a field, in that specific sense, is determined by the positions of agents in that particular field, whereas the changing position of agents will also change the structural order of the field. Therefore in every field, agents are always involved in struggling to take over authority, the authority in the form of legitimation, consecration, and prestige. Besides, such a condition will influence the correspondence between two homologous structures: the structure of works and the structure of the literary field.

Regarding its position and structure, a cultural field is believed to stand in a subordinate position within the field of power, for it possesses a high degree of symbolic forms of capital, but it lacks economic capital. That is because the legitimacy in the field of power is determined by the possession of economic or political capital. The field of power itself is defined by Bourdieu [17] as "the space of relations of force between agents or between institutions having in common the possession of capital necessary to occupy the dominant positions in different fields (notably economic or cultural)". It is the site of struggles between the holders of different power (e.g., artists and patron) that determines the transformation or conservation of different capitals' relative value, as it also determines related forces to be engaged in these struggles.

An opposition between two sub-fields forms the cultural production field structure: 'the field of restricted production' and 'the field of large scale production'. The first sub-field refers to the production of high art (e.g., 'serious literature'), where the competition between agents is merely symbolical that involves prestige, consecration, and artistic celebrity. Meanwhile, the second sub-field refers to the so-called 'mass' or 'popular' culture (e.g., mass-produced literature), in which it relies on a large and complex culture industry and economic capital based hierarchization. Although its nature is different from the field of restricted production, in Bourdieu's view, the field of large-scale production tends to adopt the spirit and dynamics from the restricted field to renew (or improve) itself.

Therefore, it can be seen that there are four basic assumptions about the literary field in the perspective of Bourdieu's genetic structuralism, as follow:

1. The literary field is $-\mathrm{a}$ space of position - formed by objective relation among different positions that its agents occupy. Thus its structural dynamics is related to the dynamics of agents position;

2. Accordingly, the literary field is a dynamic structural system that must be understood structurally, concerning the probability of agents' position changing that can also change the structural order of the literary field

3. An opposition between two sub-field also forms the structure of the literary field, 'the field of restricted production' and 'the field of large scale production';

4. The structure of literary work is homologous with the structure of the literary field, for it is believed that an agents' position and struggle in the field is the origin of the literary structure they create.

\section{Basic Assumptions on Human (Literary Agents)}

In this context, humans refer to the author and literary agent (both individual and institutional) instead. Specifically, Bourdieu's assumptions can be traced by understanding some terms, in which habitus is one of them. Habitus is generally explained by Bourdieu as a subjective system - as internalized structure - such as the scheme of perception, conception, and actions taken by members of a similar social group, that constitutes the precondition for all objectification and apperception [18] Besides, he explicates that as a concept that produces practices, habitus is also influenced by 'scheme' as an 
organized objective system engendered by history. This condition shows that habitus is a conception that structures and is structured in its objective level.

In this case, habitus is described as 'feel for the game' or a 'practical sense' that inclines agents to act and react in a particular situation. This concept refers to a set of disposition that creates practice and perception with some characteristics: durable, transposable, structured structure, and structuring structure. The first characteristic shows that habitus can last throughout the agent's lifetime. Simultaneously, the second characteristic implies that this concept can work to create practices in other fields of activity. The third characteristic shows that habitus is socially influenced or formed by objective conditions with a generative scheme. The last refers to habitus' ability to generate practices according to specific conditions.

In a more straightforward sense [19], by using the term 'hexis' that refers to the same meaning as habitus, Bourdieu tries to refer to someone's behavior, way, and style in the form of action, body gesture, or walking way. This concept is an inter-relation between the subjective world and the cultural (objective) world, where both are created and influencing one another. Accordingly, Bourdieu explicitly believes that each agent (either individual or collective) does not practice at the empty space (vacuum), but rather in a concrete social situation governed by a set of objective social relation. That social situation is called 'field', which has already been explained previously.

Due to the literary agent's practice in the literary field, the discussion will be related to what Bourdieu calls capital. In this context, capital can be understood as a set of force and power resources that agents can use to deal with the field of literature. In this case, Bourdieu categorizes capital into four types: economic capital, cultural capital, social capital, and symbolic capital. In this context, when the agents have come into a field, then all of their capitals have already automatically invested in gaining more capital from the involvement of that particular field. Therefore, the practice of producing literary work, in this case, is the manifestation of how an agent fights to struggle and gain some profit in the literary field.

Here, it is seen that there are three assumptions about human as the literary agent, as follow:

1. A literary agent is a subject whose practice is determined by their habitus structured by the generative scheme of history (objective system);

2. A literary agent is a subject whose practice (determined by habitus) to gain capital influences the dynamics of the literary field's structure. In other words, it can structure the structure of the literary field itself;

3. A literary agent is a subject whose act depends on its objective position concerning other agents in the literary field.

\section{The Feasibility for the Literary Translation Study}

After knowing the Bourdieusian sociocultural paradigm's basic assumptions, scholars in Indonesia have several kinds of potential studies to be developed. From the basic assumptions of the literary field, it can be seen that the structure of the field potentially provides an interesting object to be studied in the context of literary translation practice and production. Sapiro and Wolf propose two different kinds of prospective investigations. The first is related to the field of publishing, while the latter is focused on conceptualizing the translation field in the form of mediation space.

Sapiro emphasizes that the relevance of translation study in the field of publishing based on the Bourdieusian paradigm can lead the study on the national book market toward the international level (in which the national production is developed along with global development). In the process, book market globalization needs a framework of analysis to understand the translators' social dynamics. Accordingly, Sapiro believes that the Bourdieusian model can help compare the structure of the publishing field in many countries and assess specific agents based on the model of international circulation. As an example, she reveals how the national book market in France and the U.S have a similar structure (i.e., the opposition between small-scale and large-scale circulation).

A bit different from Sapiro, Wolf focuses on developing Bourdieu's field concept by integrating it with Bhabhasian third space concept. She eventually comes up with the concept of mediation space, in which the study on the translation field must be focused on the practice of transferring work from one to another field. In this case, she emphasizes that the transferring process is located in the in-between space called the mediation space. Therefore the production process can be investigated through the objective relation among literary translation agents and their practical strategy to distribute their capital and gain capital in that space. In this case, the structure of a translated literary work is potentially homologous with the structure and the dynamics of the mediation space.

More specifically, when it comes to the translation agent's practice, mostly the translator, Bourdieu's basic assumption on the literary agent can lead to the study on the translator's role and habitus. Accordingly, the origin of agents' particular action in translation practice can be traced comprehensively. Concerning that kind of study, Gouanvic believes that the Bourdieusian sociocultural paradigm can support the investigation of the translator's ethics and practices. He firmly claims that the translation method is influenced by the translator's habitus so that it also influenced the ethics of a translator. For him, the quality of a translated text will be determined by the translator's habitus and capital. So that the role of the translators, in this case, is to keep the quality of the work and make the target readers realize what Gouanvic terms as 'willing suspension of disbelief'. Simultaneously, the effort to fulfill that role is originated by the translators' habitus and supported by their capital. Therefore, the study on translators' practice in the production of literary translation can be conducted by investigating how they struggle to keep the target text's quality and by exploring factors such as habitus and capital that influence their translation practice. 


\section{CONCLUSION}

After understanding the basic assumptions of the Bourdieusian sociocultural paradigm and several examples of prospective literary translation studies that can be developed by Indonesian scholars, it can be seen that sociocultural study in translation studies is the potential to explore some fresh perspective for studying literary translation culture in Indonesia. Here, this study proves that the Bourdieusian sociocultural paradigm has basic assumptions that can lead a translation study to investigate the production process of literary translation, the role of translation agents, and the origin of agents' particular action in translation practice. Even though the Bourdieusian approach is not a new thing for world prominent translation scholars, it is hoped that this article can give a broad vista for those who are interested in the sociocultural study of literary translation.

\section{ACKNOWLEDGMENT}

This study is supported by The Research Fund provided by The Research Department of Universitas Gadjah Mada and academic support given by Universitas Teknokrat Indonesia.

\section{REFERENCES}

[1] M. Wolf, "The Location of the 'Translation Field', Negotiating Borderlines between Pierre Bourdieu and Homi Bhabha," in Constructing A Sociology of Translation, 1st ed., M. Wolf and A. Fukari, Eds. Amsterdam/Philadelphia: John Benjamins, 2007, pp. 109-119.

[2] J. Gouanvic, "Ethos, Ethics and Translation Ethos, Ethics and Translation Toward a Community of Destinies," The Translator, vol. 7, no. 2, pp. 2032012, 2001.

[3] J. Gouanvic, "A Bourdieusian Theory of Translation, or the Coincidence of Practical Instances," The Translator, vol. 11, no. 2, pp. 147-166, 2005.

[4] M. Inghilleri, "The Sociology of Bourdieu and the Construction of the 'Object' in Translation and Interpreting Studies," The Translator, vol. 11, no. 2, pp. 125-145, 2005.

[5] S. F. Hanna, "Hamlet Lives Happily Ever After in Arabic," The Translator, vol. 11, no. 2, pp. 167192, 2005.

[6] S. F. Hanna, "Othello in the Egyptian Vernacular," The Translator, vol. 15, no. 1, pp. 157-178, 2009.

[7] G. Sapiro, "Translation and the field of publishing," Translation Studies, vol. 1, no. 2, pp. 154-166, 2008.

[8] M. Xu, "On scholar translators in literary translation - a case study of Kinkley's translation of 'Biancheng,"' Perspective: Studies in Translatology, vol. 20, no. 2, pp. 151-163, 2012.

[9] J. Munday, Introducing Translation Studies: Theories and Applications, 4th ed. London and New York: Routledge, 2016.

[10] H. D. Dewi, "Translation Studies Research
Development in Indonesia," vol. 31, no. 2, pp 152-165, 2019.

[11] H. S. Ahimsa-Putra, Paradigma Profetik Islam. Yogyakarta: Gadjah Mada University Press, 2016.

[12] T. S. Kuhn, The Structure of Scientific Revolution. Chicago \& London: The University of Chicago Press, 1996.

[13] Faruk, Metode Penelitian Sastra, Sebuah Penjelajahan Awal. Yogyakarta: Pustaka Pelajar, 2012.

[14] W. Udasmoro, Bagaimana Meneliti Sastra? Mencermati Metodologi Dasar dalam Penelitian Sastra. Yogyakarta: Prodi Sastra Perancis FIB UGM, 2012.

[15] P. Bourdieu, The Field of Cultural Production. New York: Columbia University Press, 1993.

[16] K. Y. Karnanta, "Paradigma Teori Arena Produksi Kultural Sastra: Kajian Terhadap Pemikiran Pierre Bourdieu," Poetika, vol. 1, no. 1, pp. 3-15, 2013.

[17] P. Bourdieu, The Rules of Art: Genesis and Structure of the Literary Field. 1996.

[18] P. Bourdieu, Outline of a Theory of Practice. New York: Cambridge University Press, 1995.

[19] R. Jenkins, Membaca Pikiran Pierre Bourdieu. Bantul: Kreasi Wacana, 2013. 